\title{
An Analysis Of Histopathological Findings In Women With Postmenopausal Bleeding In A Tertiary Care Hospital
}

\author{
Dr.B.Rekha ${ }^{1}$, Dr.A.Swarupa Rani ${ }^{2}$ \\ Assistant Professors of Obstetrics \& Gyanecology, Gandhi Medical College, Secunderabad
}

\section{Introduction:}

Menopause is derived from Greek word, men (month) and pauos (to stop) ${ }^{\mathbf{1}}$.The menopause is defined by the World Health Organisation as the permanent cessation of menstruation resulting from the loss of ovarian follicular activity, an episode of bleeding 12 months or more after the last period is accepted as post-menopausal bleeding ${ }^{2}$. Common menopausal age in Indians is $45-50$ years ${ }^{3}$. Post menopausal bleeding represents approximately $5 \%$ of all gynaecological visits ${ }^{4}$.

Post menopausal bleeding represents one of the most common reason for referral to gynaecological services, largely due to suspicion of an underlying endometrial malignancy. However, postmenopausal bleeding may be the presenting symptom of cervical cancer also. Endometrial cancer is present in approximately $10 \%$ of patients referred with post menopausal bleeding. Appropriate and accurate diagnostic tests helps in early diagnosis and timely treatment and high cure rate.

About $90 \%$ of patients with endometrial carcinoma have vaginal bleeding or discharge as the presenting symptom. Therefore postmenopausal bleeding should always be investigated no matter how minimal or non persistent.

Endometrial atrophy is most common endometrial finding in women with postmenopausal bleeding accounting for $60-80 \%$. Ultrasound is the first line of diagnostic procedure to which women with postmenopausal bleeding are subjected ${ }^{5}$.

In our study the patients are evaluated by Histopathological examination (HPE) after ultrasound study confirming the thickness of endometrium being $>4 \mathrm{~mm}$. Endometrial biopsy is relatively in expensive and accurate as an office procedure. The only disadvantage of endometrial biopsy is that it is an invasive procedure. So the study was aim to investigate the clinical significance, clinical significance of PMB in terms of incidence of malignancy (HPE) to confirm diagnosis of malignancy.

\section{Aim \& Objectives:}

AIM

To analyse histopathological findings in women attending out patient department in a tertiary care hospital with post menopausal bleeding.

\section{Objectives}

- To establish the various endometrial causes of Post menopausal bleeding through histopathological evaluation.

- To correlate the clinical and histopathological findings.

- To differentiate benign and malignant lesions based on histopathology.

\section{Brief On Endometrium-Physiology And Pathology}

Atrophic Endometrium 6:

Epithelial and stromal cells are exceedingly small. Glands are hardly distinguished under low magnification or at least resembles capillaries. They are small, sparse lined by low cuboidal epithelium. Cytoplasm is scanty and mytosis lacking.

\section{Endometrial Hyperplasia ${ }^{7}$ :}

The term denotes a set of mixed epithelium and stromal proliferation that exhibits a spectrum of architectural and cytological abnormality ranging from disordered proliferative endometrium to well differentiated endometrial carcinoma. 
An Analysis Of Histopathological Findings In Women With Postmenopausal Bleeding In A ....

Classification Of Endometrial Hyperplasia $\mathbf{7}^{7}$
\begin{tabular}{|l|l|l|}
\hline $\begin{array}{l}\text { Simple Hyperplasia } \\
\text { (without atypia) }\end{array}$ & $\begin{array}{l}\text { Complex Hyperplasia } \\
\text { (without atypia) }\end{array}$ & Atypical hyperplasia \\
\hline $\begin{array}{l}\text { Tubular or cystic glands with minimal non } \\
\text { complex budding, branching or papillary } \\
\text { infoldings. }\end{array}$ & $\begin{array}{l}\text { Complex glands with frequent intraluminal } \\
\text { epithelial projections and intraglandular } \\
\text { bridging simulating cribriform structures. }\end{array}$ & $\begin{array}{l}\text { May be simple } \\
\text { (rare) or Complex } \\
\text { ( Common) }\end{array}$ \\
\hline $\begin{array}{l}\text { Glands - to- stroma ratio >3:1, Marked } \\
\text { crowding (i.e., back to back glands) rare. }\end{array}$ & $\begin{array}{l}\text { Glands - to- stroma ratio >>3:1, Marked } \\
\text { crowding with back to back glands common. }\end{array}$ & $\begin{array}{l}\text { Glands - to- stroma ratio >3:1 or >>3:1, } \\
\text { common. }\end{array}$ \\
\hline $\begin{array}{l}\text { Nuclear pseudo-stratification (nuclei } \\
\text { resemble mid - to - late proliferative } \\
\text { endometrium) Inconspicuous nucleoli, No } \\
\text { pleomorphism. }\end{array}$ & $\begin{array}{l}\text { Nuclear pseudo-stratification (nuclei resemble } \\
\text { mid - to - late proliferative endometrium) } \\
\text { Inconspicuous nucleoli, No pleomorphism. }\end{array}$ & $\begin{array}{l}\text { Nuclear pseudo-stratification with loss of } \\
\text { polack } \\
\text { nuclear size and shape often rounded. }\end{array}$ \\
\hline $\begin{array}{l}\text { Mitotic figures common, Fine nuclear } \\
\text { chromatin. }\end{array}$ & $\begin{array}{l}\text { Mitotic figures common, Fine nuclear } \\
\text { chromatin }\end{array}$ & $\begin{array}{l}\text { Mitotic figures common, Coarse or clumped } \\
\text { nuclear chromatin. }\end{array}$ \\
\hline
\end{tabular}

The classification system used by the World Health Organization (WHO) and the International Society of Gynecological Pathologists ${ }^{8}$.

designates four different types with varying malignant potential (Kurman, 1985).Hyperplasias are classified as simple and complex depending on glandular complexity and crowding .Most important, hyperplasias are further designated as atypical if they demonstrate cytologic atypia.

Only atypical endometrial hyperplasias are clearly associated with the subsequent development of adenocarcinoma.

\begin{tabular}{|l|l|}
\hline World Health Organization Classification of Endometrial Hyperplasia \\
\hline Types & Progressing to Cancer(\%) \\
\hline Simple hyperplasia & 1 \\
\hline Complex hyperplasia & 3 \\
\hline Simple atypical hyperplasia & 8 \\
\hline Complex atypical hyperplasia & 29 \\
\hline
\end{tabular}

CYSTIC GLANDULAR HYPERPLASIA:

Synchronize proliferation of glands and stroma produces endometrium that has normal gland to stromal ratio. Glands are tubular or cystically dilated with shallow budding.

\section{ADENOMATOUS HYPERPLASIA:}

Indicates glandular atypia and increased gland to stromal ratio. The malignant potential of adenomatous hyperplasia is high with severe structural and cytological atypia.

PROLIFERATIVE TYPE OF ENDOMETRIUM:

Proliferative typr of endometrium in AUB is an exageration of normal proliferative phase without significant increase in overall ratio of glands to stroma and is due to persistent eastrogen stimulation.

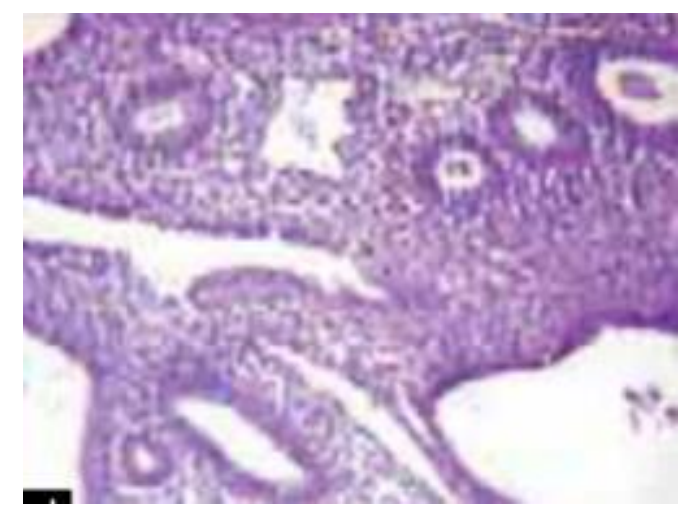




\section{ENDOMETRIAL POLYP:}

Mostly arises from hyperplasia of endometrium. Some of the endometrial lining protruding into uterine cavity as a polyp. Malignant transformation of polyp develops in $4-5 \%$ and accounts to $2-12 \%$ of cases of post menopausal bleeding.

\section{ENDOMETRIAL CANCER : \\ Risk Factors for Endometrial Cancer Factors Influencing Risk}

\section{Estimated Relative Risk}

Obesity

Polycystic ovarian syndrome

$>5$

Long-term use of high-dose menopausal 10-20 estrogens

Early age of menarche

$1.5-2$

$2-3$

$2-3$

3

1.5

$1.5-2$

$2-3$

High cumulative doses of tamoxifen $\quad 3-7$

History of diabetes, hypertension, or 1.3-3 gallbladder disease

Long-term use of high-dose combination oral $\quad 0.3-0.5$

contraceptives

Cigarette smoking

0.5

\section{Pathogenesis}

Type I and II endometrial carcinoma : Distinguishing features

\begin{tabular}{|l|l|l|}
\hline Feature & Type I & Type II \\
\hline $\begin{array}{l}\text { Unopposed } \\
\text { oestrogen menopausal status }\end{array}$ & $\begin{array}{l}\text { Present } \\
\text { pre and perimenopausal }\end{array}$ & $\begin{array}{l}\text { Absent } \\
\text { postmenopausal }\end{array}$ \\
\hline Hyperplasia & Present & Absent \\
\hline Grade & Low & High \\
\hline Myometrial invasion & Minimal & Deep \\
\hline $\begin{array}{l}\text { Specific subtypes } \\
\text { behavior }\end{array}$ & $\begin{array}{l}\text { Endometroid } \\
\text { stable }\end{array}$ & $\begin{array}{l}\text { Serous, Clear cell } \\
\text { Aggressive }\end{array}$ \\
\hline
\end{tabular}

\section{Studies on histopathological analysis of postmenopausal bleeding}

Gredmark T et al (1995) 13 studied 457 cases of postmenopausal women, 228 cases (49.90\%) had atrophic endometrium,19 cases(4.2\%) had PP(proliferative pattern), 6 cases (1.3\%) had SP(secretory pattern),12 cases $(2.6 \%)$ had BEP(benign endometrial polyp),42 cases(9.2\%) had SH(simple hyperplasia) ),40 cases(8.7\%) had, $\mathrm{CH}$ (Complex hyperplasia without atypia), 8 cases $(1.8 \%)$ had, $\mathrm{CH}$ (Complex hyperplasia with atypia), 37 cases $(8.1 \%)$ had Endo $\mathrm{Ca}$ (endometrial carcinoma), 65 cases $(14.2 \%)$ had inadequate sample.

Ind $T$ (9) (1998) 14studied 4592 cases of postmenopausal women, 2054 cases (44.74\%) had atrophic endometrium, 404cases $(8.8 \%)$ had PP(proliferative pattern), 46 cases (1\%) had SP(secretory pattern), 395 cases $(8.6 \%)$ had BEP(benign endometrial polyp), 602cases $(13.11 \%)$ had $\mathrm{SH}($ simple hyperplasia),87 cases $(1.9 \%)$ had, $\mathrm{CH}$ (Complex hyperplasia with atypia), 505cases(11\%) had Endo Ca (endometrial carcinoma), 498 cases $(10.85 \%)$ had inadequate sample.

Abha Singh A et al15 (2005) studied 55 cases of postmenopausal women, 32 cases (58\%) had atrophic endometrium, 5cases $(9 \%)$ had $\mathrm{PP}$ (proliferative pattern), 8 cases $(14.5 \%)$ had, $\mathrm{CH}$ (Comple x hyperplasia without atypia), 325 cases $(5.9 \%$ ) had, $\mathrm{CH}$ (Complex hyperplasia with atypia), 3 cases $(5.4 \%)$ had Endo Ca (endometrial carcinoma), 4 cases $(7.2 \%)$ had inadequate sample.

Bharani Bharati et al (2008)16 studied pre and postmenopausal women out of which 25 cases of postmenopausal women, 4 cases $(16 \%)$ had atrophic endometrium, 14 cases $(56 \%)$ had BEP(benign endometrial polyp), 2 cases $(8 \%)$ had, $\mathrm{CH}$ (Complex hyperplasia without atypia), 2 cases $(8 \%)$ had, $\mathrm{CH}$ (Complex hyperplasia with atypia), 3 cases(12\%) had Endo $\mathrm{Ca}$ (endometrial carcinoma).

In a Retrospective analysis of Morphological Spectrum of Endometrium in Patients Presenting with Dysfunctional Uterine Bleeding, Hematoxylin and Eosin (H\&E) stained slides of D \& C tissue were studied under light microscopy by A. Khare 17, R. Bansal et al., 2012, Out of 187 cases, 116 cases $(62 \%)$ were in reproductive age group, 47 cases $(25.1 \%)$ were of perimenopausal group and 24 cases $(12.9 \%)$ belonged to the 
postmenopausal group. For all cases clinically diagnosed as DUB, histopathological examination was done and findings were noted, they concluded that the most frequent finding seen in patients with DUB in reproductive age group was proliferative endometrium. In perimenopausal age group simple hyperplasia was most frequently noted, while in the postmenopausal age group complex hyperplasia was the predominant finding.

\title{
II. Methodology - Patients And Methods.
}

\section{Method Of Collection Of Data}

This prospective study was done at Gandhi Medical College and Hospital, Telangana, between January 2014 - August 2015 in the Department of Obstetrics \& Gynaecology in collaboration with Department of Pathology \& Radio diagnosis. Patients attending Obstetrics \& Gynecology OPD clinically with Post menopausal bleeding were selected. History of bleeding per vaginum varying from spotting per vagina, scanty flow, moderate to profuse bleeding, age of the patients, duration of symptoms, obstetric history recorded. Full assessment done by history, physical examination and investigations which include complete blood picture, fasting blood sugar, thyroid profile, renal parameters, liver function tests, clotting profile, Blood grouping and typing, viral screening and pelvic ultrasound. Transvaginal ultrasonography 22 was performed for all cases. After exclusion of adnexal (tubes and ovaries) and cervical lesions, uterus was examined to exclude any uterine lesion and to measure the endometrial thickness

(ET) in a longitudinal view of the uterus. If ET was $<4 \mathrm{~mm}$ expectant treatment was allowed but if bleeding recurred or persisted endometrial sampling was done. If ET was $>4 \mathrm{~mm}$ endometrial sampling was done immediately without resorting to the expectant treatment.

Patients with isolated endometrial causes of postmenopausal bleeding were included 29 in the study. Endometrial sample was obtained by dilatation and curettage and examined histopathologically. Chi Square $(\chi 2)$ test was used to asses risk factor analysis and percentage comparison for histopathological evaluation. The slides were reviewed and classified using current pathological criteria. The endometrial specimens were divided into the following histological categories: atrophic; proliferative; secretory; endometrial polyp; simple or cystic hyperplasia; atypical hyperplasia;carcinoma and others. The present study was approved by our institutional ethics board.

\section{Procedure}

Endometrial tissue was obtained by performing Dilatation \& curettage under local anaesthesia. The endometrial tissue was fixed in $10 \%$ formalin for 12-24 hours and the entire tissue was taken for routine processing. $5 \mu$ thickness sections taken from paraffin blocks were stained with Haematoxylin and Eosin (H\&E) and studied under light microscopy.

\author{
Sample size : 100 cases \\ Inclusion Criteria: \\ $\square$ Endometrial biopsy taken by dilatation and curettage from a Post menopausal bleeding women. \\ $\square$ Women not on any hormonal replacement therapy. \\ Exclusion Criteria: \\ $\square$ Expected cyclical bleeding that occurs in women taking sequential hormone replacement therapy.
}

\section{Observation And Results}

The following few pages will give a descriptive analysis of age distribution, parity distribution and menopause duration, medical co-morbidities distribution, type of endometrium in patients with PMB.The total numbers of patients studied were 100 from JANUARY 2014 to AUGUST 2015.

Table No.1 - Distribution of Patients According To Age:

\begin{tabular}{|lll|}
\hline Age in years & No :of patients & Percentage $(\%)$ \\
\hline $\mathbf{4 1 - 4 5}$ & 1 & $1 \%$ \\
\hline $\mathbf{4 6 - 5 0}$ & 21 & $21 \%$ \\
\hline $\mathbf{5 1 - 5 5}$ & 28 & $28 \%$ \\
\hline $\mathbf{5 6 - 6 0}$ & 36 & $36 \%$ \\
\hline $\mathbf{7 6 1}$ & 14 & $14 \%$ \\
\hline
\end{tabular}




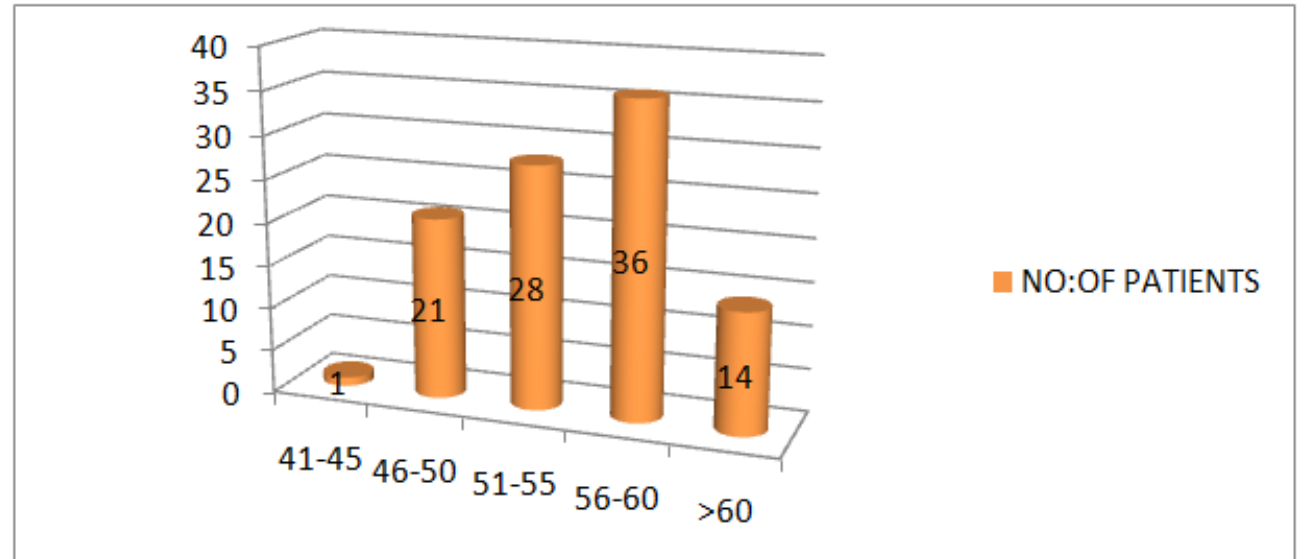

Fig No.1 Distribution of Patients According To Age

In the present study maximum number of cases (36\%) were in the age group of $56-60$ years and minimum number of cases (1\%) were in the age group of $41-45$ years. In the present study age range was 41 68 years and Mean age was 55.84 years.

Table No.2 - Distribution of Patients According To Parity:

\begin{tabular}{|lcl|}
\hline Parity & No. of patients & Percentage \\
\hline Nulli parous & 5 & $5 \%$ \\
\hline $\mathbf{1}$ & 7 & $7 \%$ \\
\hline $\mathbf{2}$ or more & 88 & $88 \%$ \\
\hline Total & 100 & $100 \%$ \\
\hline
\end{tabular}

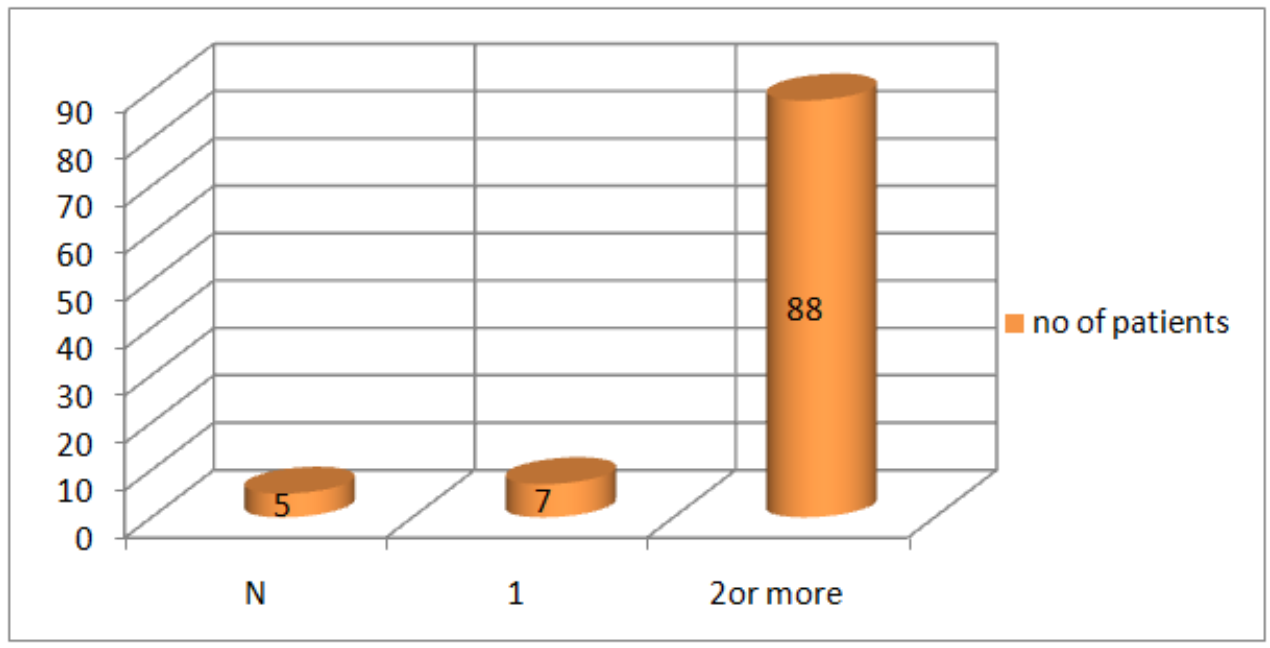

Fig No. 2 Distribution of Patients According To Parity.

The mean parity was 2.68 . The majority of patients i.e. $88(88 \%)$ had a parity of 2 or more, 5 were nulliparous.

Table No.3 - Distribution of Patients according to Duration Of Menopause:

\begin{tabular}{|lll|}
\hline Duration in years & No. of patients & Percentage \\
\hline $\mathbf{1}-\mathbf{5}$ & 40 & $40 \%$ \\
\hline $\mathbf{6}-\mathbf{1 0}$ & 45 & $45 \%$ \\
\hline$>\mathbf{1 0}$ & 15 & $15 \%$ \\
\hline Total & 100 & $100 \%$ \\
\hline
\end{tabular}




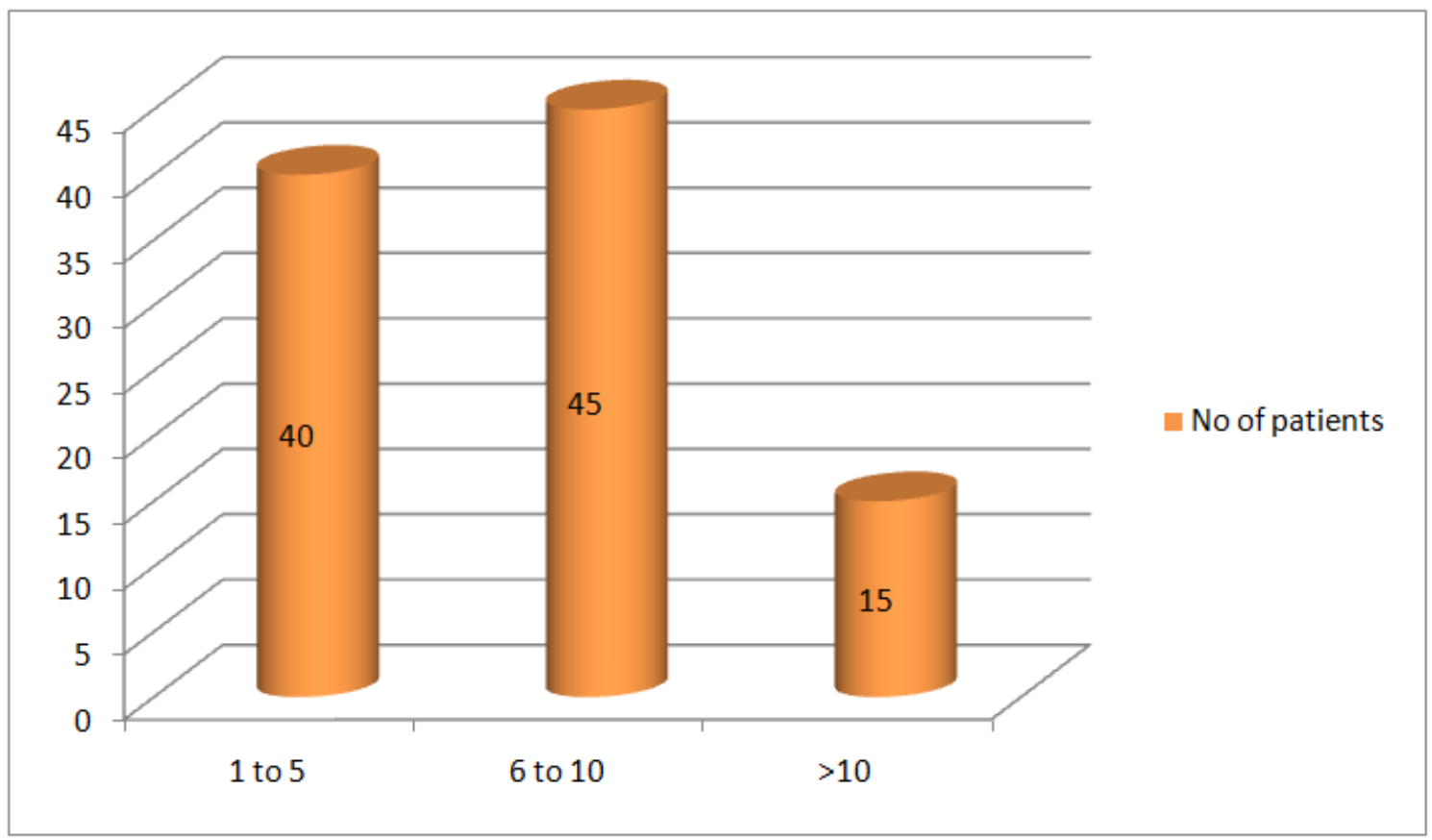

Fig No.3 - Distribution Of Patients according to Duration Of Menopause.

Postmenopausal bleeding was more common within 6-10yrs after reaching menopause. Maximum number of patients $(45 \%)$ had duration of menopause between 6-10 years, indicating inverse relationship between duration of menopause and frequency of postmenopausal bleeding.

Table No.4- Distribution of patients with medical co-morbid conditions.

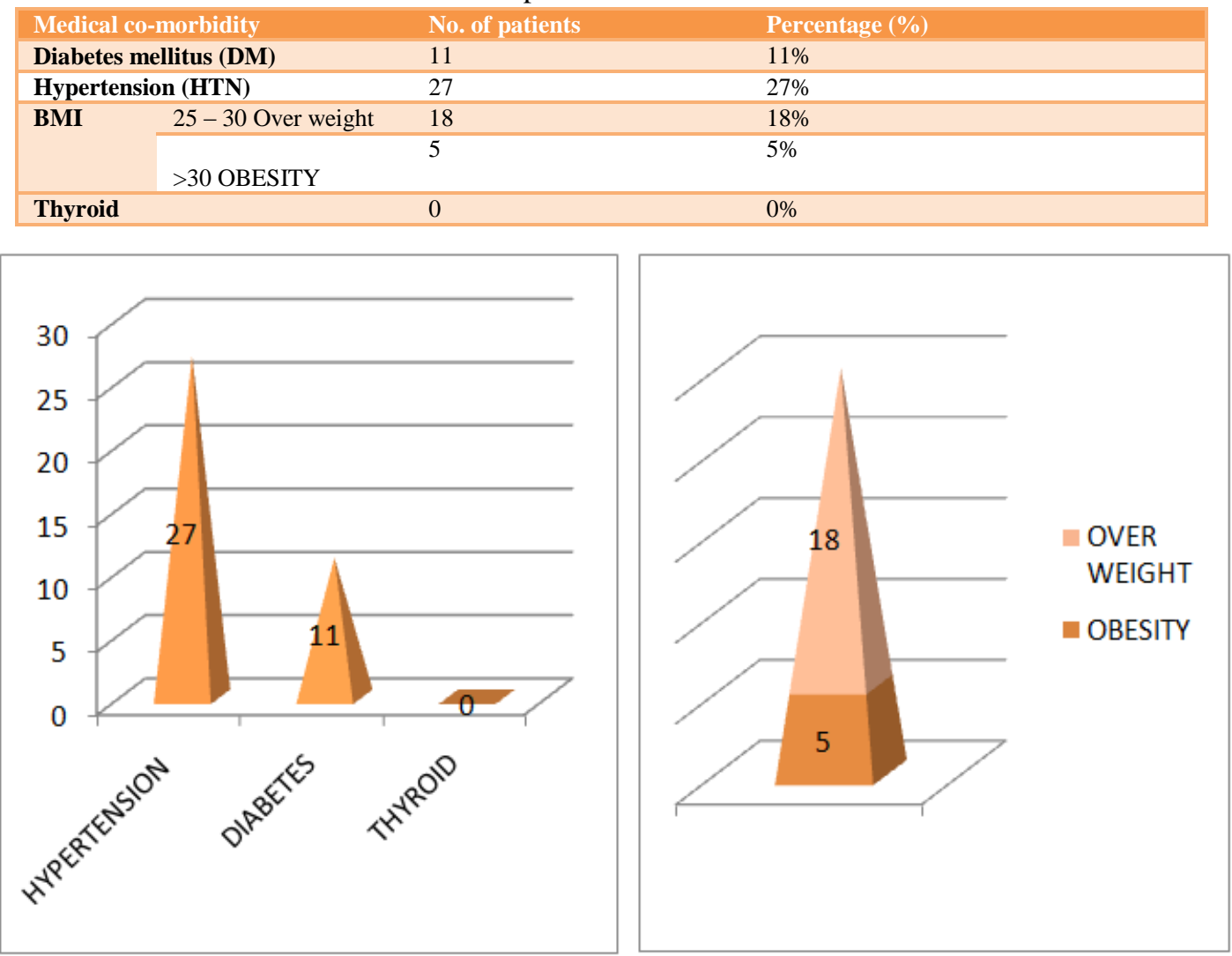

Fig No.4 - Distribution Of Patients With Medical Co-Morbid Conditions.

In the present study $43 \%$ patients are associated with medical comorbidities $(p<0.05)$. They are the independent risk factors associated with postmenopausal bleeding. 
An Analysis Of Histopathological Findings In Women With Postmenopausal Bleeding In A ....

Table No.5 -Histopathological Findings Of Endometrium.

\begin{tabular}{|l|l|l|l|}
\hline \multicolumn{2}{|c|}{ Histopathology } & No.of patients & Percentage (\%) \\
\hline Atrophic & Without atypia & 31 & $31 \%$ \\
\hline \multirow{3}{*}{ Simple hyperplasia } & With atypia & 27 & $27 \%$ \\
\hline Proliferative & 4 & $4 \%$ \\
\hline Secretory & 21 & $21 \%$ \\
\hline Endometrial polyp & 5 & $5 \%$ \\
\hline Endometrial carcinoma & 4 & $4 \%$ \\
\hline Endometritis & 6 & $6 \%$ \\
\hline Not Representative & 1 & $1 \%$ \\
\hline Total & 1 & $1 \%$ \\
\hline
\end{tabular}

In the present study histopathological findings are Atrophic endometrium (AE) 31\%, Simple hyperplasia $(\mathrm{SH})$ without atypia $27 \%$, Simple hyperplasia $(\mathrm{SH})$ with atypia $4 \%$, Proliferative endometrium (PE) $21 \%$, Secretory endometrium (SE) 5\%,Endometrial polyp (EP)4\%, Endometrial carcinoma(EC)6\%, Endometritis $1 \%$ and Not Representative(NR) $1 \%$.

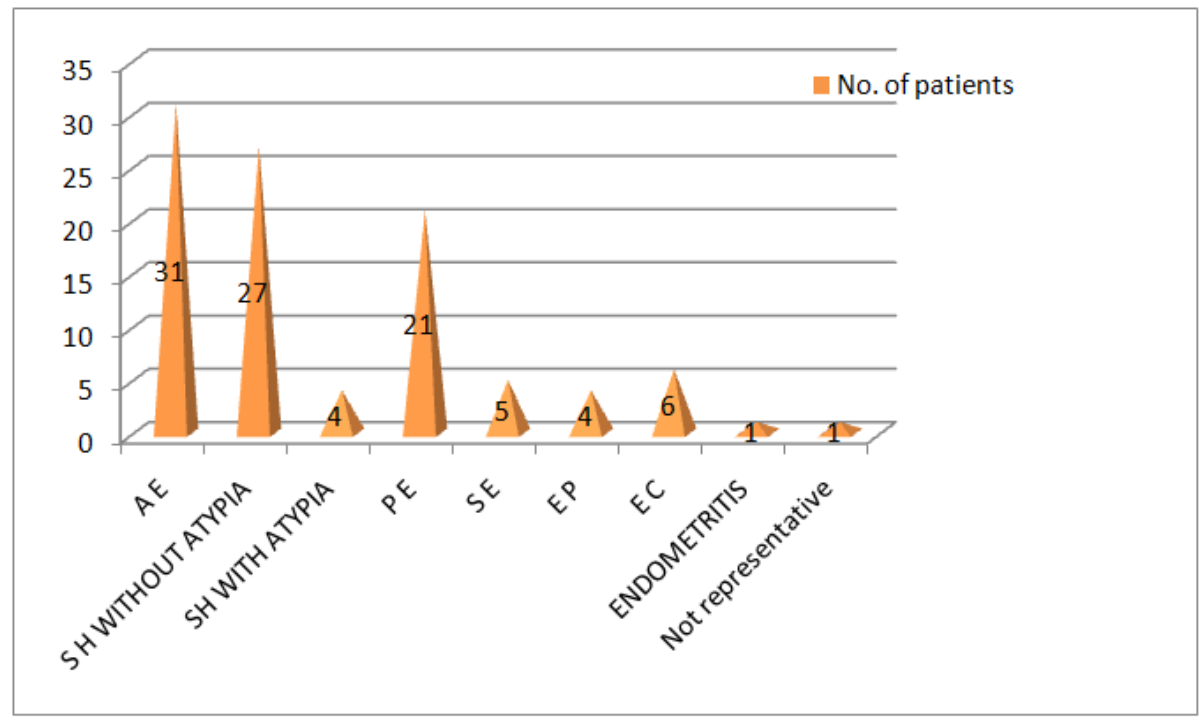

Fig No.5 -Histopathological Findings Of Endometrium.

It was observed that atrophic endometrium was the most common histological diagnosis i.e. in 31 cases (31\%) followed by different types of endometrial hyperplasia in 31(31\%). Proliferative endometrium was observed in $21 \%$ of cases and one case $(1 \%)$ of endometritis was seen.

Table No.6 - Distribution of Benign and Malignant Histopathological Findings.

\begin{tabular}{|lll|}
\hline Histopathological findings & No. Of Patients & Percentage $(\%)$ \\
\hline Benign & 94 & $94 \%$ \\
\hline Malignant & 6 & $6 \%$ \\
\hline Total & 100 & $100 \%$ \\
\hline
\end{tabular}




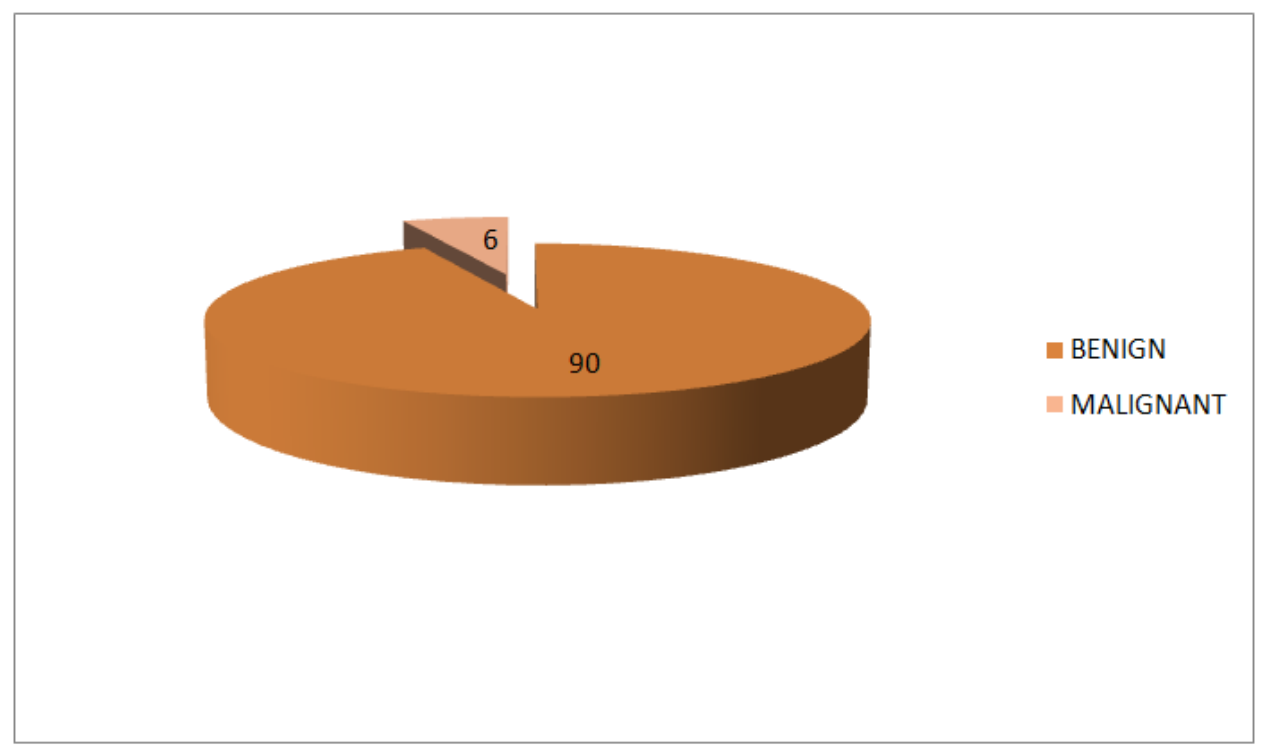

Fig No.6 - Distribution of Benign And Malignant Histopathological Findings.

In our study of endometrial curettage of 100 cases who presented with complaints of postmenopausal bleeding, benign conditions were seen in (90\%) cases which included atrophic endometrium, proliferative endometrium, secretory endometrium, benign endometrial polyp, endometritis and simple hyperplasia without atypia. Premalignant conditions such as hyperplasia with atypia seen in 4 (4\%).

The malignant endometrial adenocarcinoma in 6 cases $(6 \%)$.

Table No.7-Distribution Of Different Benign And Malignant Pathologies In Different Age Groups.

\begin{tabular}{|c|c|c|c|c|c|c|c|c|c|}
\hline \multirow{3}{*}{$\begin{array}{l}\text { Age } \\
\text { groups(yrs) }\end{array}$} & \multicolumn{9}{|c|}{ HISTOPATHOLOGICAL FINDING ( PERCENTAGE) } \\
\hline & \multirow[t]{2}{*}{$\mathrm{AE}$} & \multicolumn{2}{|l|}{$\mathrm{S} \mathrm{H}$} & \multirow[t]{2}{*}{ PE } & \multirow[t]{2}{*}{$\mathrm{SE}$} & \multirow[t]{2}{*}{ EP } & \multirow[t]{2}{*}{ EC } & \multirow[t]{2}{*}{ ENDOMETRITIS } & \multirow[t]{2}{*}{$\mathrm{NR}$} \\
\hline & & $\begin{array}{l}\text { WITHOUT } \\
\text { ATYPIA }\end{array}$ & $\begin{array}{l}\text { WITH } \\
\text { ATYPIA }\end{array}$ & & & & & & \\
\hline $41-45$ & - & 1 & - & - & - & - & - & - & \\
\hline $46-50$ & 4 & 8 & - & 5 & 2 & - & - & 1 & \\
\hline $51-55$ & 6 & 7 & 1 & 9 & 2 & 1 & - & - & 1 \\
\hline $56-60$ & 13 & 7 & 3 & 7 & 1 & 3 & 2 & - & \\
\hline$>61$ & 8 & 4 & - & - & - & - & 4 & - & \\
\hline TOTAL & 31 & 27 & 4 & 21 & 5 & 4 & 6 & 1 & 1 \\
\hline
\end{tabular}

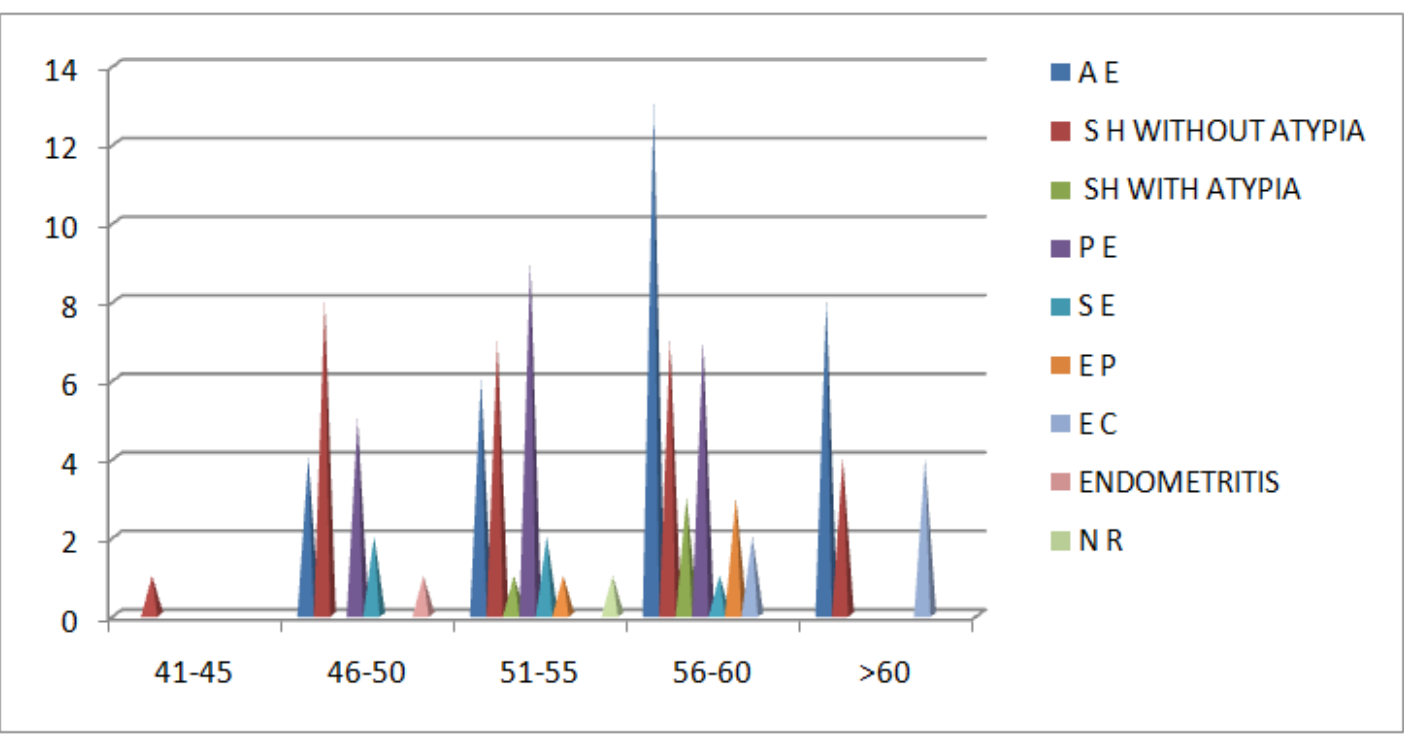

Fig No.7 - Distribution Of Different Pathologies In Different Age Groups. 
In the present study simple hyperplasia without atypia was common $(8 \%)$ in the age group 46-50 years, proliferative endometrium was common (9\%) in the age group (51-55) years, and atrophic endometrium was common in the age group more than 56 years.Endometrial carcinoma was common in age group more than 56 years.

Tab No-8; Histopathological frequency in relation to time of onset after menopause.

\begin{tabular}{|l|l|l|l|l|}
\hline $\begin{array}{l}\text { Onset Of PMB After } \\
\text { Menopause }\end{array}$ & Malignant cases & Benign value & P & 40 \\
\hline 1-5 years & - & 40 & 45 & \\
\hline 6-10 years & 2 & 43 & 15 & \\
\hline$>10$ years & 4 & 11 & 15 \\
\hline
\end{tabular}

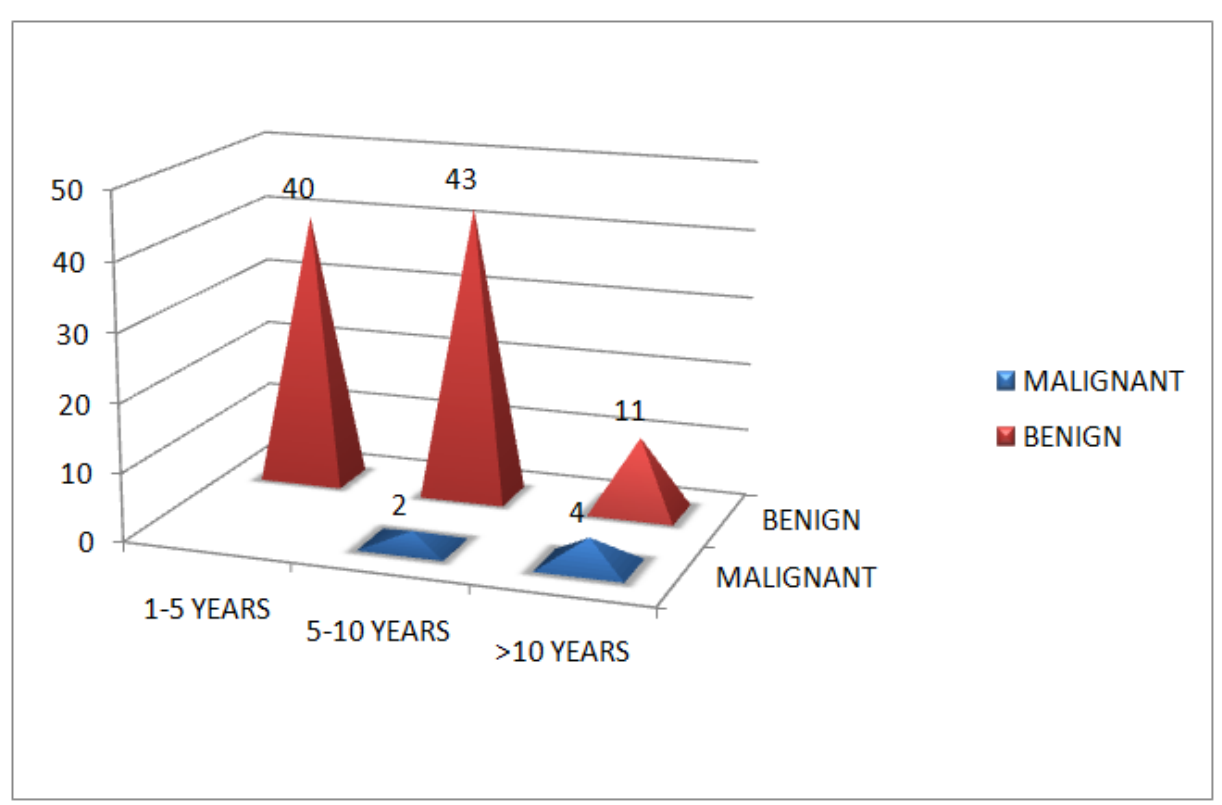

Fig No-8; Histopathological frequency in relation to time of onset after menopause.

In the present study, benign lesions were seen in 40 cases with duration of menopause 1-5 years, 43 cases with duration of menopause 6-10 years and in 11 cases with duration of menopause more than 10 years. Whereas malignant cases were seen with duration of menopause more than 6 years.2malignant cases were seen with duration of menopause 6-10 years and 4 with duration of menopause more than 10 years.

Tab No.9 Comparison of parity with endometrial carcinoma.

\begin{tabular}{|l|l|}
\hline Parity & Endometrial carcinoma( \%) \\
\hline Nullipara & 1 \\
\hline $\mathbf{2}$ 0r more & - \\
\hline
\end{tabular}

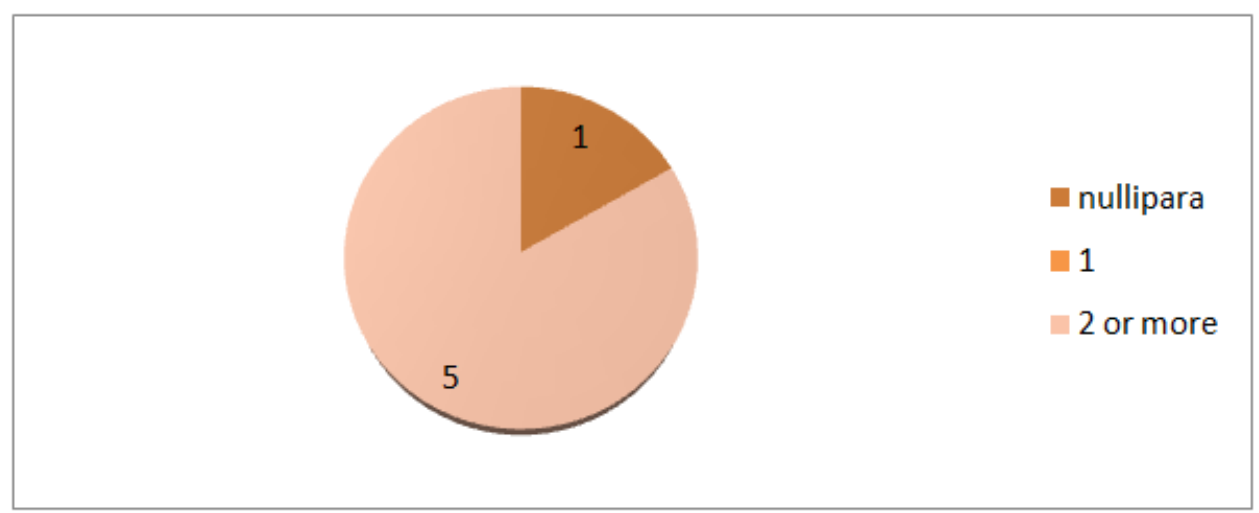

Fig No. 9 Comparison of parity with endometrial carcinoma.

Only one case out of five cases of nullipara presented with postmenopausal bleeding was diagnosed with endometrial carcinoma. There was a statistical significance $(\mathrm{p}<005)$. 


\section{Discussion}

The present prospective study includes 100 patients presented with post menopausal bleeding to gynaecology OP department. The famous dictum that "Postmenopausal bleeding must be considered as indicative of malignant disease until proven otherwise," still holds true in our circumstances ${ }^{23}$. The general consensus regarding management of PMB is that all patients must be excluded of cancer by biopsy.

Table No.1 - Distribution Of Patients According To Age:

\begin{tabular}{|l|l|l|}
\hline Age in years & No .of patients & Percentage $(\%)$ \\
\hline $41-45$ & 1 & $1 \%$ \\
\hline $46-50$ & 21 & $21 \%$ \\
\hline $51-55$ & 28 & $28 \%$ \\
\hline $56-60$ & 36 & $36 \%$ \\
\hline$>61$ & 14 & $14 \%$ \\
\hline
\end{tabular}

In the present study maximum number of cases (36\%) were in the age group of $56-60$ years and minimum number of cases (1\%) were in the age group of $41-45$ years. While in the study of kothapally et al maximum number of cases were between 50-60 yrs (56.6\%) and minimum in the age group of 45 to 50 yrs

Table No.12 - Comparision Of Distribution Of Patients According To Duration Of Menopause With Other Studies:

\begin{tabular}{|l|l|l|}
\hline \multirow{2}{*}{ Duration in years } & No. of patients & Present study \\
\cline { 2 - 3 } & Sonali rathi et al $(\mathrm{N}=174)^{29}$ & $40 \%$ \\
\hline $1-5$ & $32.76 \%$ & $45 \%$ \\
\hline $6-10$ & 47.12 & $15 \%$ \\
\hline$>10$ & $20.12 \%$ & $100 \%$ \\
\hline Total & $100 \%$ & $100 \%$ \\
\hline
\end{tabular}

Postmenopausal bleeding was more common within 6-10yrs after reaching menopause. Maximum number of patients $(45 \%)$ had duration of menopause between 6-10 years, similar to Opmeer B et al ${ }^{30}$ ,Kothapally $\mathbf{K}$ et al, indicating inverse relationship between duration of menopause and frequency of postmenopausal bleeding.

Tab No-8; Histopathological frequency in relation to time of onset after menopause

\begin{tabular}{|l|l|l|l|l|}
\hline $\begin{array}{l}\text { Onset Of PMB After } \\
\text { Menopause }\end{array}$ & Malignant cases & Benign value & Total \\
\hline 1-5 years & - & 40 & 40 & \\
\hline 6-10 years & 2 & 43 & 45 & \\
\hline$>10$ years & 4 & 11 & 15 & \\
\hline
\end{tabular}

In 4 of 6 patients with endometrial carcinoma, malignancy was present when bleeding started $>10$ years after menopause. The incidence of malignancy increased with increase in period between menopause and onset of PMB. Number of benign cases were prominent in the 1- 10 years of onset of menopause.

Table No.13 - comparision of Distribution of patients with medical co-morbid conditions with other studies:

\begin{tabular}{|c|c|c|c|}
\hline \multicolumn{2}{|c|}{ Medical co-morbidity } & Kothapalli et al & Present study \\
\hline \multicolumn{2}{|c|}{ Diabetes mellitus (DM) } & $13.36 \%$ & $11 \%$ \\
\hline \multicolumn{2}{|c|}{ Hypertension (HTN) } & $36.6 \%$ & $27 \%$ \\
\hline \multirow[t]{2}{*}{ BMI } & $25-30$ Over weight & $43.3 \%$ & $18 \%$ \\
\hline & $>30$ OBESITY & 0 & $5 \%$ \\
\hline \multicolumn{2}{|c|}{ Thyroid } & $3.3 \%$ & $0 \%$ \\
\hline
\end{tabular}

Sonali rati et all $(\mathrm{N}=174) 48.2 \%$ patients had associated medical disorders which is statistically significant, present study has $43 \%$ patients associated with medical comorbidity $(\mathrm{p}<0.05)$. They are the independent risk factors associated with postmenopausal bleeding. In Sonali rati et all study, $42.42 \%$ obese patients, $23 \%$ diabetic patients, $20 \%$ hypertensive patients and $40 \%$ nulliparous women had endometrial carcinoma which was statistically significant $(\mathrm{p}<0.05)$.

In the Present study $33.3 \%$ of patients with endometrial carcinoma had medical comorbidity, $16.6 \%$ of patients with endometrial carcinoma had obesity.

It was observed that atrophic endometrium was the most common histological diagnosis i.e. in 31cases (31\%) followed by different types of endometrial hyperplasia in $31(31 \%)$. The incidence of atrophy was found to be $49.9 \%$ by Gredmark T et al , $52.1 \%$ by Lee WH et $\mathbf{a l}^{31}, 64.4 \%$ by Dangal G et $\mathbf{~ a l}^{32}$ and $53 \%$ by Kaur $\mathbf{M}$ et $\mathbf{a l}{ }^{33}$. They all reported endometrial atrophy as the commonest finding in patients with postmenopausal bleeding which is consistent with the present study. Philip $\mathbf{H}$ et $\mathbf{a l}^{\mathbf{3 5}}$ found atrophic endometrium (13.3\%) as the

DOI: 10.9790/0853-1509140112 www.iosrjournals.org $\quad 10 \mid$ Page


third most common cause after proliferative endometrium. Meyer et $\mathbf{a l}^{\mathbf{3 6}}$ postulated sclerotic degeneration of endometrial vessels as a cause of bleeding in atrophic endometrial. Hourihan et al stated anatomical vascular variations or local abnormal haemostatic mechanisms in the uterus as a cause of bleeding from atrophic endometrium. Simple endometrial hyperplasias without atypia were observed in $27 \%$ and it was the second most common finding next to atrophic endometrium. In other studies it ranged from $13.46 \%$ to 26.6\%.Endometrial hyperplasia is a pathological condition of the endometrium which carries both clinical and pathological significance. It is one of the most important predisposing factors for the development of endometrial carcinoma. This risk is especially seen in atypical endometrial hyperplasia which carries the risk of associated endometrial carcinoma more than endometrial hyperplasia without atypia. In our study, atypical hyperplasia was observed in $4 \%$. It was found to range from 1.8 to $8 \%$ in other studies.

In the present study, proliferative endometrium was observed in $21 \%$ which is comparable to the study of Phillip $\mathbf{H}$ et al who found $20 \%$. It was observed to range from $4.2 \%$ to $25.92 \%$ in other studies, which was also observed in previous studies done by Kothapally $\mathrm{K}$ et al6, Caspie et al.

\section{Surgical-Pathologic Finding}

\begin{tabular}{|l|l|}
\hline Histology & Percentage of Patients \\
\hline Adenocarcinoma & 80 \\
\hline Adenosquamous & 16 \\
\hline Other (papillary serous, clear cell) & 4 \\
\hline
\end{tabular}

Modified from Creasman WT, Morrow CP, Bundy BN, et al. Surgical pathologic spread patterns of endometrial cancer. Cancer1987;60:2035-2041

Endometrial adenocarcinoma which is the most important and threatened cause of postmenopausal bleeding, was found in $6 \%$ in the present study, while others have found it to range from $6 \%$ to $12 \%$. Histologically there were 6 cases of endometrioid adenocarcinoma. In obesity, there is increased peripheral conversion of adrenal androgen to estrogen by aromatization in adipocyte. Diabetes mellitus is associated with increase in estrogen level, hyperinsulinemia or elevated level of insulin like growth factor I (IGF-I). In nulliparity, there is prolonged unopposed estrogen stimulation. Estrogen induces glandular proliferation leading to thickening of endometrium.

Table No.6 Distribution of Benign \& Malignant Histopathological findings.

\begin{tabular}{|l|l|l|}
\hline Histopathological findings & No. Of Patients & Percentage (\%) \\
\hline Benign & 93 & $93 \%$ \\
\hline Malignant & 6 & $6 \%$ \\
\hline Not representative & 1 & $1 \%$ \\
\hline Total & 100 & $100 \%$ \\
\hline
\end{tabular}

In our study of endometrial curettage of 100 cases which presented with complaints of postmenopausal bleeding, benign conditions were seen in (90\%) cases which included atrophic endometrium, proliferative endometrium, secretory endometrium, benign endometrial polyp, endometritis and simple hyperplasia without atypia. Premalignant conditions such as hyperplasia with atypia seen in 4 (4\%). The malignant endometrial adenocarcinoma in 6 cases $(6 \%)$.

In the present study pathology remained not representative in $1 \%$ of cases, which is lower than

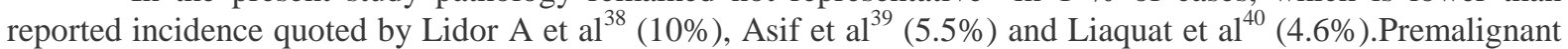
lesions like atypical hyperplasia were seen in $(4 \%)$ patients. The malignant cases included endometrial carcinomas in $6(6 \%)$ cases.

Tab No.14- Comparing frequency of malignancies in various studies

\begin{tabular}{|l|l|l|c|}
\hline Study & Year & Cancer cervix & Cancer endometrium \\
\hline Sengupta A9, et al & 1990 & $32 \%$ & $8 \%$ \\
\hline Kothapally K6, et al & 2013 & $10 \%$ & $6.6 \%$ \\
\hline Pragati jkarmakar et al & 2014 & $6.6 \%$ & $4 \%$ \\
\hline Present study & 2015 & - & $6 \%$ \\
\hline
\end{tabular}

\section{Conclusions \& Recommendations:}

1. Postmenopausal bleeding is a symptom not to be ignored.

2. The results showed that atrophic endometrium was the most common cause..

3. A definitive diagnosis of post-menopausal bleeding is made by histology.

4. Malignancy cannot be ruled out until proved otherwise and justifies a thorough evaluation of patients with this symptom along with histopathological confirmation.

5. Though the main aim of evaluation of cases of postmenopausal bleeding is to exclude premalignant and malignant lesions of the endometrium, majority of cases had benign causes for post menopausal bleeding.

DOI: 10.9790/0853-1509140112 $\quad$ www.iosrjournals.org $\quad 11 \mid$ Page




\section{Summary}

The present prospective study includes 100 patients presented with post menopausal bleeding to gynaecology OP department. The general consensus regarding management of PMB is that all patients must be excluded of cancer by oriented biopsy.

In the present study maximum number of cases (36\%), were in the age group of 56 - 60 years and minimum number of cases (1\%) were in the age group of 41- 45 years. Age range was 41- 68 years and Mean age in the present study was 55.84 years. Postmenopausal bleeding was more common within 6-10yrs after reaching menopause. Maximum number of patients (45\%) had duration of menopause between 6-10 years.

The incidence of malignancy increased with increase in period between menopause and onset of PMB. Number of benign cases were prominent in the 1-10 years of onset of menopause. In 4 of 6 patients with endometrial carcinoma, malignancy was present when bleeding started $>10$ years after menopause.

The risk of endometrial cancer in women with post menopausal bleeding rises with age, peak incidence was observed in the age group of 55-70yrs. The mean parity was 2.68 . The majority of patients i.e. $88(88 \%)$ had a parity of 2 or more , 5 were nulliparous. Only one case out of five cases of nullipara presented with postmenopausal bleeding was diagnosed with endometrial carcinoma.

In the Present study $33.3 \%$ of patients with endometrial carcinoma had medical comorbidity, $16.6 \%$ of patients with endometrial carcinoma had obesity, which is statistically significant.

The histopathological findings are Atrophic (AE) 31,\%Simple hyperplasia (SH) without atypia 27\%, Simple hyperplasia (SH) with atypia 4\%, Proliferative(PE)21\%, Secretory(SE) 5\%,Endometrial polyp (EP)4\%, Endometrial carcinoma(EC)6\%, Endometritis1\% and Not Representative(NR)1\%.

It was observed that atrophic endometrium was the most common histological diagnosis i.e. in 31 cases (31\%) followed by different types of endometrial hyperplasia in $31(31 \%)$.

In our study of endometrial curettage of 100 cases which presented with complaints of postmenopausal bleeding, benign conditions were seen in (90\%) cases which included atrophic endometrium, proliferative endometrium, secretory endometrium, benign endometrial polyp, endometritis and simple hyperplasia without atypia. Premalignant conditions such as hyperplasia with atypia seen in 4 (4\%). The malignant endometrial adenocarcinoma in 6 cases $(6 \%)$. The malignant cases included endometrial carcinomas in 6(6\%) cases.

Post Menopausal bleeding was managed according to the current Guidelines. Thus Dilatation \& curettage can be recommended in peripheral centers with limited facilities as it is an easy procedure, sophisticated equipment is not required and this gives chance to differentiate benign and malignant lesions in postmenopausal bleeding .

\section{References}

[1]. Dawood NS, Peter K, Ibrar F, Dawood A. Postmenopausal bleeding: causes and risk of genital tract malignancy. J Ayub Med Coll Abbottabad 2010; 22:117-20.

[2]. W.H.O. Research on the menopause in the 1990s. Report of a WHO Scientific Group. World Health Organization technical report series 1996;866:1-107.;

[3]. Tandulwadkar S, Deshmukh P, Lodha P, Agarwal B. Hysteroscopy in postmenopausal bleeding. J Gynec Endosc Surg 2009;1: 8993.

[4]. Carlos RC, Bree RL, Abrahamse PH, Fendrick AM. Cost effectiveness of saline assisted hysterosonography and office hysteroscopy in the evaluation of postmenopausal bleeding. Acad Radiol 2001; 8: 835-4.

[5]. Jonathan S. Berek MD, MMS, Berek \& Novaks Gynecology ,14 edition.Lippincott Williams \& Wilkins 2007 2.p no 1343.]

[6]. Ian A.R. More Normal endometrium. Chapter -1 Haines and Taylor Text book of Obstetrics\&Gynaecological Pathology, $4^{\text {th }}$ Edn, Vol.1, Edt. H. Fox, Wells, London,Churchill Livingstone, 1995; 365 to 381pp.

[7]. Longacare, Richard, Michael. Endometrial hyperplasia, metaplasia carcinoma, Chapter - 13, Haines and Taylor text book of Obstetrics \& Gynaecological pathology, $4^{\text {th }}$ Edn, Vol 1, Edt.H. Fox, Wells, London, Churchill Livingstone, 1995; 421-439pp.

[8]. JohnO.Schorge,MD,JosephI.Schaffer,MD,LisaM.Halvorson,MD,BarbaraL.Hoff man,M D, KarenD.Bradshaw,MD,F. Gary Cunningham, MD. Et al., Williams Gynecology The McGraw-Hill Companies;2008 